\title{
Research on the Direct Strength Calculation of a 70000 DWT Bulk Carrier
}

\author{
Liang FENG ${ }^{1,2, a}$, Chunbo ZHEN ${ }^{3, b}$, Ruikeng Feng ${ }^{2, c}$, Sheng Dong ${ }^{2, d}$
}

1, Shandong Provincial Key Laboratory of Ocean Engineering, Qingdao 266100,China

2, College of Engineering,Ocean University of China, Qingdao 266100,China.

\section{3,Transportation Equipments \& Ocean Engineering College, Dalian Maritime University, Dalian 116026, China

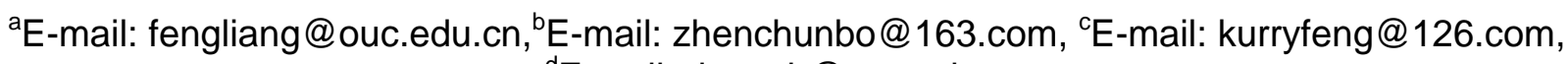 ${ }^{\mathrm{d} E}$-mail: dongsh@ouc.edu.cn}

Keywords: Bulk Carrier; Structural strength; direct calculate; FE

Abstract. The direct strength calculation of a $70000 \mathrm{t}$ bulk carrier was carried out based on the Guidelines for Direct Analysis of Bulk Carriers. Through building finite element model of 70000 DWT Bulk Carrier's hold section, the design Loads, boundary conditions and load cases were studied. According to the direct strength calculation purposed by CCS, the yield strength and buckling strength were calculated to compare with Guidelines. The result shows that the stress of the transverse bulkhead and double bottom girder is larger.

\section{Introduction}

Ship design and structural analysis is the basic prerequisite to ensure ship safety, and moreover, how to undertake more effectively on the hull design and structural strength analysis is very important for the safety of the ship[1-4]. Improving bulk carrier safety during the operation has become an international prosperous research area, and the ship's structural strength of new built and having been put to use must be checked to ensure the safety of bulk carriers.

In this paper, the Structural Simulation analysis for one 70000 DWT bulk carrier is studied. According to the rules[5-6], the structure strength is calculated according to the direct calculate method used FE analysis.

\section{Finite element model}

The 3-D FE model is used for direct calculation and analysis of primary members' strength of oil tanks. The extent of $1 / 2$ hold length forward and 1 hold length in the middle and $1 / 2$ hold length aft within mid-ship cargo area in longitudinal direction, and full depth of the ship in vertical direction. Where the tanks in the mid-ship cargo region are of different lengths, the middle tank of the finite element model is to represent the cargo tank of the greatest length. The finite element model may be prismatic. Both port and starboard sides of the ship are to be modelled. The full depth of the ship is to be modelled. In general, the results of the middle hold, including bulkhead, are used for strength assessment.

All main longitudinal and transverse structural elements are to be modelled. These include inner and outer shell, double bottom floor and girder system, transverse and vertical web frames, stringers and transverse and longitudinal bulkhead structures. All plates and stiffeners on the structure, including web stiffeners, are to be modelled.

The FE model is to be represented using a right handed Cartesian co-ordinate system, where:

(a). $\mathrm{x}$ is measured in the longitudinal direction, positive forward from the aft perpendicular

(b). $\mathrm{y}$ is measured in the transverse direction, positive to port from the centerline

(c). $\mathrm{z}$ is measured in the vertical direction, positive upward from the baseline

According to the rule above, the whole ship FE model are shown in Fig.1. 


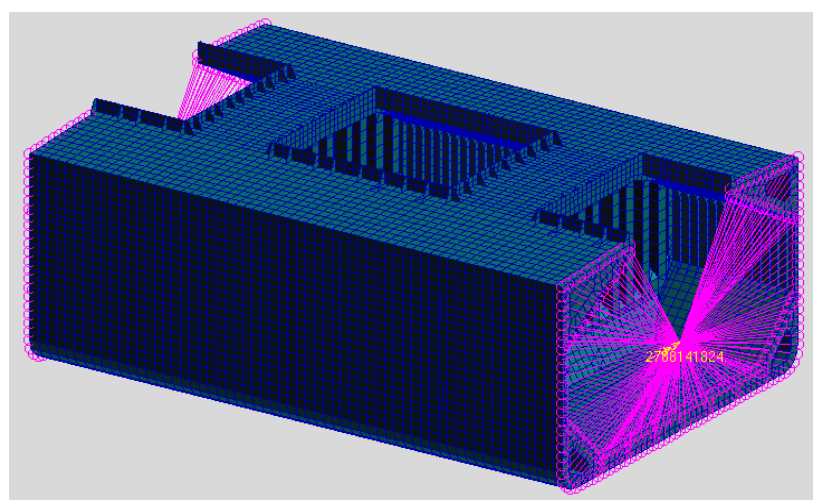

Fig.1 The whole ship FE model

\section{Design Loads}

While at sea, ships are subjected to wave-induced load, in addition to buoyancy, cargo loads and corresponding inertial loads.

\subsection{Still water loads}

Still water load are consist of weight distribution curve and buoyancy curve

Break up the weight of various items (hull steel, equipments, fittings and cargoes) along ship's length into the trapezoid weight distribution blocks and superimpose the blocks to form weight distribution curve $\mathrm{w}(\mathrm{x})$ in the given conditions.

In the balanced floating condition of the ship, the buoyancy of the ship in still water can be determined by the draft. Therefore the buoyancy curve $b(x)$ along ship's length can be obtained based on the ship's lines.

\section{2 wave loads}

The wave bending moment $\mathrm{Mw}$ is to be determined in accordance with the Rules, positive as hogging.

$$
\left\{\begin{array}{l}
M_{w v-h o g}=190 M C L^{2} B C_{b} \times 10^{-3} \\
M_{w v-\text { sag }}=-110 M C L^{2} B\left(C_{b}+0.7\right) \times 10^{-3}
\end{array}\right.
$$

\subsection{Cargo pressure in tank}

The cargo pressure in tank is to be obtained from the following equations:

$$
\mathrm{P}=\rho_{0} g(\mathrm{~h}+2.5)
$$

Where, $\rho_{0}$ is the density of liquid cargo in tank, but not less than $0.85 \mathrm{t} / \mathrm{m}_{3}$; $\mathrm{h}$ is the vertical distance from tank top to the point considered, in $\mathrm{m}$.

\subsection{External sea pressure}

The external water pressure may be determined by the following methods:

(1)Full loading condition

External water pressure includes hydrostatic pressure and hydrodynamic wave pressure, and is determined as follows.

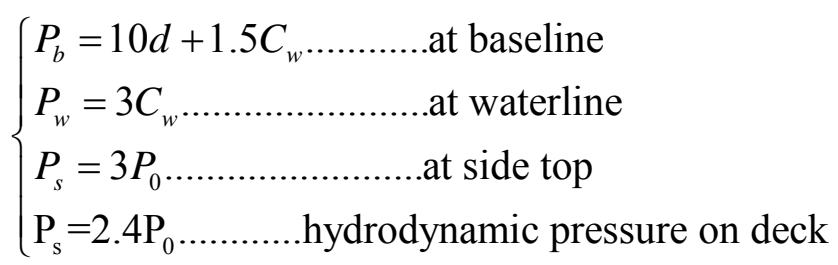

(2) Other loading conditions 


$$
\left\{\begin{array}{l}
P_{b}=10 d_{a} \ldots \ldots \ldots \ldots \text { at baseline } \\
P_{w}=0.0 \ldots \ldots \ldots \ldots . . . \text { at waterline }
\end{array}\right.
$$

The formula for calculation of hydrodynamic pressure at baseline, waterline and side top are given as above. The external water pressure at other side positions is to be determined by linear interpolation.

\subsection{Bending moment of end planes}

The bending moment applied on end planes of the FE model is to be the actual moment of the planes, including still water bending moment $\mathrm{M}_{\mathrm{s}}$ and wave bending moment $\mathrm{M}_{\mathrm{w}}$.

\section{Load cases}

The standard load cases are complied with rule $[5,6]$. The purpose of these load cases is to ensure that the longitudinal, transverse and shear strength of the hull structure complies with the acceptance criteria.

\section{Boundary conditions}

Because the load is symmetrical on port and starboard sides, the displacements in transverse direction of nodes on longitudinal centerline plane are constrained, and the rotations about the two coordinate axes on longitudinal centerline plane are constrained, i.e. $\delta y=\theta x=\theta z=0$.

Constraint of end planes: the independent point at one end constrains $\delta \mathrm{x}, \delta \mathrm{y}, \delta \mathrm{z}, \theta \mathrm{x}, \theta \mathrm{z}$, and the independent point at the other end constrains $\delta \mathrm{y}, \delta \mathrm{z}, \theta \mathrm{x}, \theta \mathrm{z}$, as indicated in Table 1.

Table 1 Application of Boundary Conditions

\begin{tabular}{c|c|c|c|c|c|c}
\hline \multirow{2}{*}{ Position } & \multicolumn{3}{|c|}{ displacement constraint } & \multicolumn{2}{c}{ rotation constraint } \\
\cline { 2 - 7 } & $\delta \mathrm{x}$ & $\delta \mathrm{y}$ & $\delta \mathrm{z}$ & $\theta \mathrm{x}$ & $\theta \mathrm{y}$ & $\Theta \mathrm{z}$ \\
\hline Longitudinal centerline section & - & Cons. & - & Cons. & - & Cons. \\
\hline End plane A & Link & - & Link & - & Link & Link \\
\hline End plane B & Link & - & Link & - & Link & Link \\
\hline Rigid point A & Cons. & Cons. & Cons. & Cons & BM & Cons \\
\hline Rigid point B & - & Cons. & Cons. & Cons & BM & Cons \\
\hline
\end{tabular}

\section{Result}

As space is limited, this paper only gives stress contour in some load cases, see Fig.2. And the calculation result in all 9 load cases are shown in Tab.2.

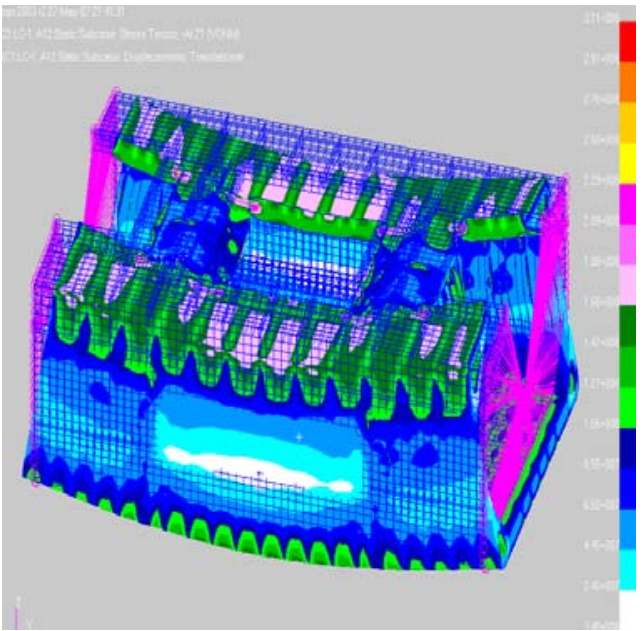

(a) load case1

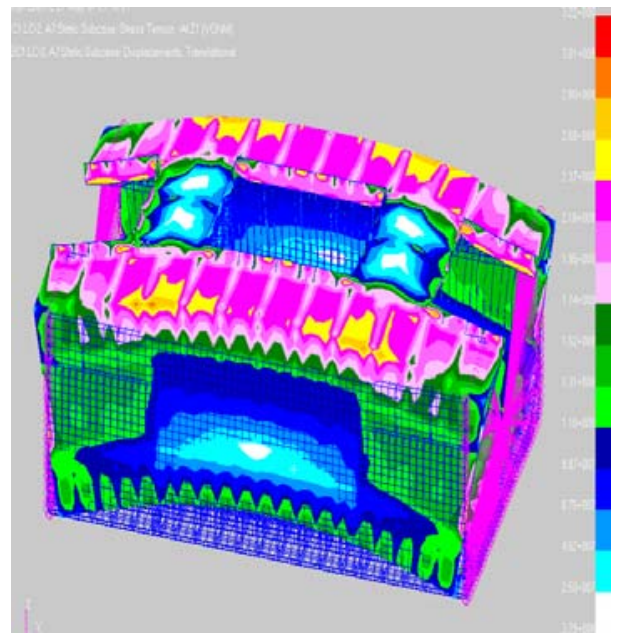

(b) load case 2 


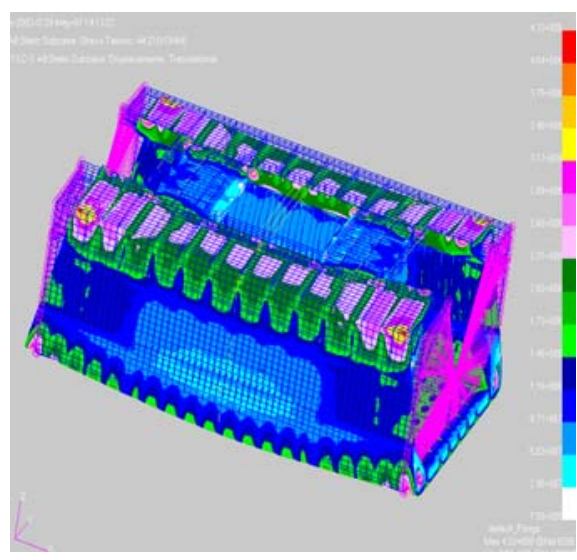

(c) load case 3

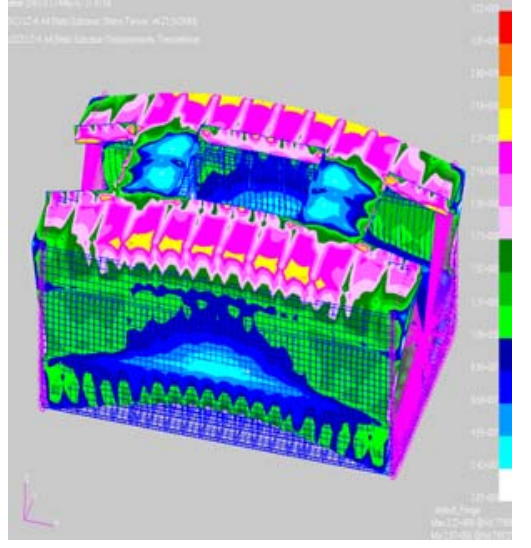

(d) load case 4

Fig.2 Stress contour in some load cases

Table 2 Results of strength check (Mises, MPa)

\begin{tabular}{c|c|c|c|c|c|c}
\hline \multirow{2}{*}{ position } & \multicolumn{6}{|c}{ Stress } \\
\cline { 2 - 7 } & Lc1 & Lc2 & Lc3 & Lc4 & Lc5 & Lc6 \\
\hline outside shell plating & 194.828 & 203.656 & 219.410 & 255.008 & 304.286 & 257.397 \\
\hline deck plating & 217.583 & 274.225 & 280.507 & 256.164 & 314.387 & 260.590 \\
\hline transverse bulkhead & 176.865 & 135.987 & 160.208 & 162.76 & 190.053 & 160.329 \\
\hline double bottom girder & 262.890 & 206.592 & 225.144 & 271.76 & 331.17 & 258.867 \\
\hline floor & 151.685 & 198.324 & 157.017 & 306.06 & 169.170 & 314.546 \\
\hline
\end{tabular}

\section{Conclusion}

From the Stress contour and calculation result, we can see that the stress of all the elements do not exceed the maximum permissible stress criteria. The stress of transverse bulkhead and double bottom girder are much larger, they are the main load-bearing structure. More attention should be paid to these structure designs. The result can offer the reference for the bulk carrier ship's design and development.

\section{Acknowledgement}

This study is supported by the Fundamental Research Funds for the Central Universities (201513042).

\section{References}

[1]Zhu T Y, Toshiyuki S. Design lo ads used for direct strength assessment of merchant ship structures [J].The American Society of Mechanical Engineers, 2007,129(2):120-130.

[2]ZHANG Shaoxiong, CHEN Nanhua, ZHANG Wei. T he whole ship structural strength direct analysis for the 8000t river to sea Barge[J]. Ship \&Ocean Engineering, 2005(5): 39- 41.

[3]BAI Jianwei, LI Runpei, GU Yongning, et al .Structural strength analysis o f container vessel using entire ship FE model[J]. Ship Engineering, 2000(5):8-11.

[4]ZHU Shengchang, CHENG Qingqiang. Numeral method for accurately determining the boundary forces of 3D FEM model of three cargo holds[J].Journal of Ship Mechanics, 2006,10(1):71-79.

[5] China Classification Society. Guidelines for Direct Analysis of Oil Tankers [S]. Beijing: China Communication Press, 2003.

[6] China Classification Society. Guidelines for Direct Analysis of bulk carriers [S]. Beijing: China Communication Press, 2003. 